Article

\title{
Optimization of Dispatching Electricity Market with Consideration of a Solar-Assisted Coal-Fired Power Generation System
}

\author{
Rongrong Zhai ${ }^{1, *}$, Lingjie Feng ${ }^{1}$, Hai Yu ${ }^{2}$, Chao $\mathrm{Li}^{1}{ }^{1}$ and Yongping Yang ${ }^{1}$ \\ 1 School of Energy Power and Mechanical Engineering, North China Electric Power University, Beijing 102206, \\ China; fenglj1995@163.com (L.F.); Lichao201408@163.com (C.L.); yypncepu@163.com (Y.Y.) \\ 2 CSIRO Energy, 10 Murray Dwyer Circuit, Mayfield West, NSW 2304, Australia; hai.yu@csiro.au \\ * Correspondence: zhairongrong01@163.com
}

Received: 2 March 2019; Accepted: 28 March 2019; Published: 3 April 2019

check for updates

\begin{abstract}
This study investigates the multi-objective optimization of load dispatch of a solar-assisted coal-fired power generation system. The improved environmental/economic load dispatch model considers coal consumption, $\mathrm{NO}_{\mathrm{x}}$ emissions, and power purchase cost. The singular weighted method is utilized to solve this multi-objective and multi-constraint optimization problem. A power system that includes five power generators, one of which is retrofitted to a solar-assisted coal-fired unit, is also analyzed. It can be concluded that the loads of solar-assisted coal-fired units are higher than the original coal-fired unit, and with the increase of solar radiation, the gap between the loads of two units also increases. In addition, after retrofitting, the coal consumption, the $\mathrm{NO}_{\mathrm{x}}$ emission, and power costs of units reduce by about $2.05 \%, 0.45 \%$, and $0.14 \%$, respectively. From the study on the on-grid power tariff, where the tariff drops from 16.29 cents/ $\mathrm{kWh}$ to 3.26 cents $/ \mathrm{kWh}, \mathrm{NO}_{\mathrm{x}}$ emissions drop from $12.31 \mathrm{t}$ to $11.28 \mathrm{t}$ per day, a reduction of about $8.38 \%$. The cost of purchasing electricity decreases from $\$ 2,982,161.8$ to $\$ 2,020,505.0$ per day, a decrease of $32.25 \%$. Therefore, when both coal-fired units and solar-assisted coal-fired units exist in a region, the use of solar-assisted coal-fired power generation units should be prioritized.
\end{abstract}

Keywords: Solar-assisted coal-fired power generation system; Singular weighted method; load dispatch

\section{Introduction}

The load dispatch of a power generation system is defined, on the basis of the efficiency, power, and other properties of each unit, as the arrangement of loads for the units [1]. The traditional load dispatch problem is to find the best way to arrange the power output from all types of generating plants to realize the maximum economic benefits. However, air pollution poses a serious threat to human health and the environment [2]. In China, the government has pressed various policies to address these problems. In terms of reducing pollutant emissions, the government has focused on industries. Pollutant emissions of the industries mostly come from coal-fired power generation. By the end of 2018, approximately 70\% of the electricity in China was still derived from coal-fired power generation systems [3]. One way to deal with this situation is to exploit renewable energy to replace coal-fired power generation. Solar energy is a clean, renewable energy that can meet the energy demands of people. Solar-assisted coal-fired units that utilize various types of solar thermal systems for coupling traditional coal-fired power plants not only reduce pollutants and greenhouse gas emissions but also reduce the investment of solar energy facilities. Research by Wang et al. [4] showed the local influence on solar-assisted coal-fired power generation system (SCPGS) performance due to the substitution 
of chemical exergy by solar thermal exergy and the global influence on SCPGS performance jointly determines the final coal-savability for a SCPGS in a superposition manner. The superposition effect (the interaction of local influence and global influence) shows that the overall coal saving capability of SCPGS depends not only on the direct benefits brought by the local integration of solar energy, but also on the overall superposition effect of the integration on the system components. The comprehensive evaluation factor $(\mathrm{f})$ is proposed on the premise of giving consideration to both the coal-savability and efficiency-promotability. By the end of 2018, the power generating capacity of grid-connected solar power was 174.63 million $\mathrm{kW}$, an increase of 33.9\% year-on-year [3].

Previous studies demonstrated that solar thermal technology is mature enough and that the combination of solar energy and coal-fired units is feasible. Desai et al. [5] proposed a method to determine a thermodynamic and cost-effective design for solar power plants without hybridization and storage. Some studies mainly focused on the use of thermal storage systems in solar thermal energy generation systems. Raul et al. [6] conducted experiments on a single spherical capsule and a lab-scale setup to investigate melting, and analyzed the effect of capsule diameter and porosity on the LHTES (based latent heat thermal energy storage). The results showed that the energy stored and extraction are faster for a smaller capsule diameter and higher porosity. Lakhani et al. [7] considered a multitube shell and tube latent heat thermal storage system, and found that the LHTES system with a lower overall diameter and longer length provides better overall performance for a solar thermal power plant. Corgnale et al. [8] studied solar power plants from the aspect of thermal energy storage systems and found that the selected storage systems with metal hydride high-temperature materials can achieve and exceed the requirements, such as volumetric energy density $\left(25 \mathrm{kWhth} / \mathrm{m}^{3}\right)$ and operating temperature $\left(600^{\circ} \mathrm{C}\right)$. Yogev et al. [9] researched an operating strategy based on thermal storage with the latent heat of phase change materials (PCMs) and indicated that these PCMs can achieve stable power output without any heat transfer enhancement. Therefore, these materials can reduce the complexity and cost of the storage system. Ehrhart et al. [10] found a large gap between the design point with annual average performance (mainly due to the solar field and receiver subsystems) and energy losses because of the thermal energy storage being full to capacity. Eduard et al. [11] used life-cycle assessment to compare the environmental impacts of different thermal energy storage systems and found that the systems based on solid and liquid media exerted the lowest and the highest environmental impact per kWh stored, respectively. Other scholars studied the operating performance of solar-assisted coal-fired power generation systems. Eric et al. [12] proposed the concept of the solar-assisted coal-fired unit, which increases the efficiency and reduces the greenhouse gas emission of the traditional power plant. Yang et al. [13] took a $200 \mathrm{MW}$ unit as an example and found that using medium- or low-temperature solar heat to replace the extraction can achieve a solar heat-to-power conversion efficiency of $36.5 \%$ for solar heat at $260^{\circ} \mathrm{C}$. Hong et al. [14] studied a $330 \mathrm{MW}$ coal-fired power plant hybridized with solar heat in Sinkiang Province, China, and found that the levelized cost of electricity generation could be $20 \%$ to $30 \%$ lower than that of the solar-only thermal power plant.

Some studies proposed different methods to solve the problem of load distribution. Bhattacharjee et al. [15] proposed the real coded chemical reaction algorithm to solve the economic emission load distribution problem. In this method, they considered $\mathrm{NO}_{\mathrm{x}}$ emissions, power demand equality constraint, and operating limit constraint. Jeddi et al. [16] proposed a new modified harmony search algorithm to solve the economic load dispatch problem and combined the economic emission load dispatch problem. Leena et al. [17] proposed use of Artificial Neural Networks, which are based on Levenberg Marquardt backpropagation Algorithm (LMBP), to make rapid decisions in the load scheduling center and solve the economic load dispatch problem. Coelho et al. [18] proposed particle swarm optimization approaches to solve the economic load dispatch problem. Another researcher studied the problem of electricity load distribution by considering wind power. Li et al. [19] proposed a stochastic multi-objective optimization method to solve the security-constrained optimal power flow problem with wind power and distributed load changing. This method considers the minimum expectation of fuel costs, the maximum wind power penetration with wind speed, and distributed load 
changes. Mondal et al. [20] proposed the gravitational search algorithm to solve the economic emission load dispatch problem by considering both thermal generators and wind turbines with the minimum amount of $\mathrm{NO}_{x}$ emissions and fuel costs. Aghaei et al. [21] presented a scenario-based stochastic programming framework to model the random nature of load demand and wind forecast errors. Taking empirical data as input, Modarresi et al. [22] formulated the look-ahead real-time economic dispatch problem using the scenario approach, which generated a quantifiable risk level in real-time economic scheduling and generated direct benefits to both real-time and intra-day decision making processes. Zhu et al. [23] proposed a decomposition-based multi-objective evolutionary algorithm to optimize the load distribution problem. Rizk et al. [24] proposed a new improved search algorithm based on parallel hurricane search optimization for non-smooth constrained economic emission dispatch problems to solve the nonlinear constrained economic emission dispatch problem. The results show that this method is superior to other optimization methods. Roy [25] gave the formulation of the maximum likelihood load dispatch, as well as Karush-Kuhn-Tucker conditions of its optimal solution, in order to reduce the impact of the instability of solar energy on grid connection; it is also a method for making certain operation reserves for solar energy. However, operating reserves may lead to a significant increase in solar grid connection costs. Modarresi et al. [26] introduced a new method of quantifying operation reserves in power systems with high intermittent resource utilization rate, and introduced an intuitive and rigorous risk diagram, which will help to obtain more cost-effective operation reserves while ensuring system reliability, load probability loss, and other performance indexes.

Only a few studies have analyzed solar-assisted coal-fired units from the aspect of load dispatch of the power generation system. In our previous work, we have done a lot of research on solar-assisted coal-fired power units on their unit features, performances analysis, integration optimization, and so on. Based on the previous work, how to make solar-assisted coal-fired power generation adapt to the complex and changeable environment of a power grid is further considered. In the present study, a coal-fired unit is retrofitted into a solar-assisted coal-fired unit, and the other remaining units are not changed. Under the given power demand, the multi-objective model considers coal consumption, $\mathrm{NO}_{x}$ emissions, and power purchase cost. The original and retrofitted units are compared and analyzed. This study may be used as a guide to propose appropriate policies that encourage and promote the development of solar-assisted coal-fired units.

\section{Problem Description}

The load dispatch of the power generation system is that the administrative office arranges loads for the power generating units on the basis of the efficiency, power, and other properties of each unit. Load distribution on the distribution of the energy and the operation of an electric power system is highly important. The load dispatch of the power generation changes with the operational characteristic of a unit. Therefore, the load dispatch of the power generation in this area changes when a solar-assisted coal-fired unit is introduced to the energy supply system. This study analyzes the changes in load dispatch when the coal-fired unit is retrofitted to a solar-assisted coal-fired unit. The diagram of the solar-assisted coal-fired system is shown in Figure 1. The system mainly contains "solar side" and "coal-fired side" parts. The "solar side" is composed of a solar collector system and heat exchange system. Solar collector plant is though collector plant form, in which the working medium is thermal oil. The heat exchanger is an oil-water heat exchanger. When the oil passes through the heat exchanger, its temperature decreases. When the water passes through the exchanger, its temperature increases. The solar collectors are produced by LUZ International, Ltd. A solar collector assembly is $47.1 \mathrm{~m}$ long with an aperture width of $5 \mathrm{~m}$. The heat is absorbed in a steel absorber tube which is $66 / 70 \mathrm{~mm}$ in diameter, surrounded by an evacuated glass envelop which is $115 / 120 \mathrm{~mm}$ in diameter. The concentration ratio is about 71 and the collector focal length is $1.49 \mathrm{~m}$. The parabolic trough axes are oriented due north-south to track the sun from east to west.

In the coal-fired side, the unsaturated feedwater from the condenser enters into the boiler after going through the condensate pump, four low-pressure reheaters (H5, H6, H7, and H8), a deaerator, 
a feedwater pump, and three high pressure reheaters ( $\mathrm{H} 1, \mathrm{H} 2$, and $\mathrm{H} 3)$. Then the feedwater absorbs heat in the boiler and becomes superheated steam. The superheated steam from the boiler is transported to the high-pressure cylinder in the turbine to produce power. The steam from the high-pressure cylinder goes into the boiler and is reheated in order to improve work capacity. Then, the reheated steam is transported to intermediate pressure and lower pressure cylinders to produce power. In the end, the final exhaust is condensed in the condenser.

As shown in the diagram, feed water from the deaerator enters the heat exchanger and absorbs the solar heat. Four modes of operation are available according to the heat exchanger outlet temperature of the feedwater.

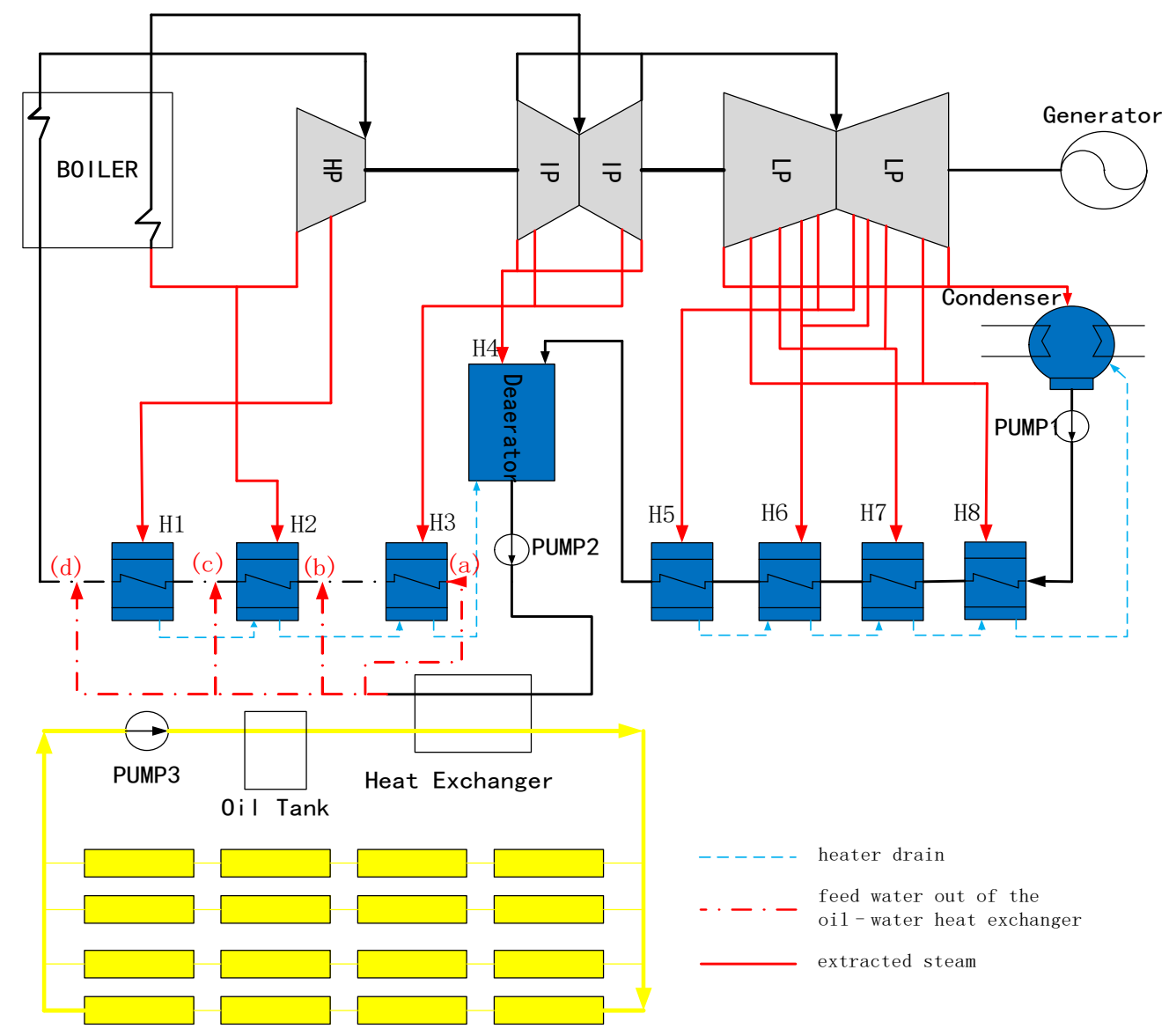

Figure 1. Diagram of solar-assisted coal-fired system.

(1) When the temperature of feed water out of the oil-water heat exchanger is lower than that of the original third heater. The feed water enters the third heater. This mode is shown in (a) position.

(2) When the temperature of the feed water out of the oil-water heat exchanger is lower than that of the original second heater but higher than that of the original third heater. The feed water enters the second heater. This mode is shown in (b) position.

(3) When the temperature of feed water out of the oil-water heat exchanger is lower than that of the original first heater but higher than that of the original second heater. The feed water enters the first heater. This mode is shown in (c) position.

(4) When the temperature of feed water out of the oil-water heat exchanger is higher than that of the original first heater. The feed water enters the boiler. This mode is shown in (d) position. 


\section{Methodology}

Under certain constraints, multi-objective optimization aims to have more than one goal to achieve an optimal solution. One of the easiest ways to obtain the optimal solution is called standard quantization or the singular weighted method. A weight is assigned to each target. All the targets with their own weights are positioned together, and then the problem is solved under the same constraints of the original problem. The obtained solution is a solution to the original problem (called the Pareto solution). The weight arrangement is constantly changed; hence, different optimal solutions are obtained. The present study takes the units in a particular area as an example, simultaneously considering coal consumption, nitrogen oxide emissions, and electricity purchase. Then, the optimal solution and the load dispatch of each unit are obtained under the power demand in this region.

\subsection{Objective Function}

\subsubsection{Minimum Coal Consumption}

Coal consumption is a commonly used index in the evaluation of coal-fired power plants. Therefore, minimizing the coal consumption of coal-fired power plants is crucial in modern energy systems.

$$
\min f_{1}=\sum_{j=1}^{N}\left[a_{j} P_{j}^{2}(t)+b_{j} P_{j}(t)+c_{j}\right]
$$

where $N$ is the number of units; $a_{j}, b_{j}$, and $c_{j}$ are the coefficients of coal consumption; and $P_{j}(t)$ is the current output of the power plant.

\subsubsection{Minimum Pollutant Emissions}

Pollutant emission performance during power production is considered, and the function of minimum pollutant emissions is established in various energy systems by fitting the discharge curves of various energy systems. In this study, all the units are equipped with desulphurization equipment with an efficiency of above $98 \%$. Therefore, the main consideration emissions of units are $\mathrm{NO}_{\mathrm{x}}$ emissions.

$$
\operatorname{minf}_{2}=\sum_{j=1}^{N}\left[u_{j} P_{j}^{2}(t)+v_{j} P_{j}(t)+w_{j}\right]
$$

where $u_{j}, v_{j}$, and $w_{j}$ are the coefficients of pollutant emission.

3.1.3. Minimum Power Costs

$$
\min f_{3}=\sum_{j=1}^{N} \rho_{j}(t) P_{j}(t)
$$

where $\rho_{j}(t)$ is the current power purchase cost.

\subsection{Constraints}

\subsubsection{Load Balance between Supply and Demand}

Load balance between supply and demand means that the power output and the electricity should be equal at any time.

$$
\sum_{j=1}^{N} P_{j}(t)=P_{D}(t)+P_{L}(t)
$$

where $P_{L}(t)$ stands for the grid loss and $P_{D}(t)$ stands for the grid power requirement. 


\subsubsection{Upper and Lower Limits for the Units}

The power generation of the units is deeply influenced by the characteristics of the units. For example, a coal-fired power plant should work least at the load ratio of approximately $30 \%$ to avoid extra oil consumption. The characteristics of different types of units should be considered to determine the upper and lower limits for the units.

$$
P_{\text {jmin }} \leq P_{j}(t) \leq P_{\text {jmax }}
$$

where $P_{j \min }$ and $P_{j \max }$ represent the lower and upper limits for the units, respectively.

\subsection{Multi-Objective Optimization}

The method for solving multi-objective function has rapidly developed. Some scholars proposed multi-objective differential evolution algorithms to solve problems [27-31]. Ghasemi [32] proposed improved multi-objective interactive honey bee mating optimization to solve the environmental/economic power dispatch problem. In this method, the fuel costs, pollutant emissions, and system loss should be minimized while satisfying certain system constraints. Boyhina et al. [33] proposed a trust region algorithm to solve the multi-objective economic emission load dispatch problem. The approach they proposed is efficient for solving ill-defined systems and non-convex multi-objective optimization problems.

The aim of conventional generation planning is to minimize the cost of power generation under conditions that meet the system constraints and electricity demand. Considering the lowest operating costs, fuel cost, or electricity purchase is a single objective function.

\subsubsection{Singular Weighted Method}

In accordance with the weight of the original objective function, a new objective function $\mathrm{g}(\mathrm{x})$ is constructed. The solution of the single-objective optimization function can be the efficient solution of the problem.

$$
g(x)=w_{1} \frac{f_{1}}{f_{1}^{\text {min }}}+w_{2} \frac{f_{2}}{f_{2}^{\text {min }}}+\ldots+w_{m} \frac{f_{m}}{f_{m}^{\text {min }}}
$$

where $f_{i}^{\min }=\min _{x \in s} f_{i}(x),(i=1,2, \ldots, m)$ is the lowest solution of the single objective function; $f^{\text {min }}=$ $\left(f_{1}^{\min }, f_{2}^{\min }, \ldots, f_{m}^{\min }\right)$ is the optimal solution vector with all the elements denoting the optimal solution for each objective function; $w=\left(w_{1}, w_{2}, \ldots, w_{m}\right)$ is the weighted vector, and $\sum_{j=1}^{N} w_{i}=1, w_{i} \geq 0, i=1,2$, $\ldots, m$. In this model, $\frac{f_{i}}{f_{i}^{m i n}}$ is used to convert the different objective functions to the same magnitude.

The effective solution of the multi-objective function can be solved by solving the single objective function $\min _{x \in s} g(x)$.

\subsubsection{Realization of the Algorithm Using MATLAB}

According to the singular weighted method, objective functions (1) to (3) can be converted to

$$
g(x)=w_{1} \frac{f_{1}}{f_{1}^{\text {min }}}+w_{2} \frac{f_{2}}{f_{2}^{\text {min }}}+w_{3} \frac{f_{3}}{f_{3}^{\text {min }}}
$$

where $f_{1}^{\min }, f_{2}^{\min }$, and $f_{3}^{\min }$ stand for the optimal values of objective functions (1) to (3), respectively, and can be derived by solving the corresponding single-objective functions; and $w_{1}, w_{2}$ and $w_{3}$ stand for specified weight coefficients and known quantities. Equation (7) is simplified by removing the constant term to obtain 


$$
\begin{aligned}
g(x) & =w_{1} \frac{\sum_{j=1}^{N}\left[a_{j} P_{j}^{2}(t)+b_{j} P_{j}(t)\right]}{f_{1}^{\min }}+w_{2} \frac{\sum_{j=1}^{N}\left[u_{j} P_{j}^{2}(t)+v_{j} P_{j}(t)\right]}{f_{2}^{\min }}+w_{3} \frac{\sum_{j=1}^{N} \rho_{j}(t) P_{j}(t)}{f_{3}^{\min }} \\
& =\sum_{j=1}^{N}\left[\left(\frac{w_{1} a_{j}}{f_{1}^{\text {min }}}+\frac{w_{2} u_{j}}{f_{2}^{\text {min }}}\right) P_{j}^{2}(t)\right]+\sum_{j=1}^{N}\left[\left(\frac{w_{1} b_{j}}{f_{1}^{\text {min }}}+\frac{w_{2} v_{j}}{f_{2}^{\text {min }}}+\frac{w_{3} \rho_{j}}{f_{3}^{\min }}\right) P_{j}(t)\right]
\end{aligned}
$$

Therefore, the original problem can be solved by solving the objective function (8) under constraints (4) and (5). Quadprog function, a toolbox in MATLAB, can be used to solve quadratic programming problems.

General quadratic programming problems can be described as [34]

$$
\begin{gathered}
\text { Objective Function : } \min \left(\frac{1}{2} x^{T} H x+f^{T} x\right) \\
\text { Constraints : }\left\{\begin{array}{c}
A x \leq B \\
A_{e q}=B_{e q} \\
x_{m} \leq x \leq x_{M}
\end{array}\right.
\end{gathered}
$$

Equation (9) can be solved by MATLAB.

Syntax:

$$
\left[x, f_{\text {opt }}, \text { flag, } c\right]=\text { quadprog }\left(H, f, A, B, A_{e q}, B_{e q}, x_{m}, x_{M}, x_{0}\right)
$$

where $H$ is the Hessian matrix of the quadratic programming objective function, $f$ is the vector of the coefficients of $x, A$ is the matrix for linear inequality constraints, $B$ is the vector for linear inequality constraints, $A_{e q}$ is the matrix for the linear equality constraints, $B_{e q}$ is the vector for the linear equality constraints, $x_{m}$ is the vector of lower bounds, $x_{M}$ is the vector of upper bounds, and $x_{0}$ is the initial point for $x$. If the constraint of matrix does not exist, an empty matrix is used to replace it. After the optimized operation finishes, the results will be returned in variable $x$, and the result of the optimization objective function will be returned in $f_{\text {opt }}$. If the flag is a positive number, the equation is solved successfully. The number of iterations and the number of function calls, algorithms, and other information will be returned in variable $c$.

\section{Case Study}

\subsection{Basic Data}

\begin{tabular}{|c|c|c|c|c|c|c|c|c|c|}
\hline \multirow{3}{*}{ Unit No. } & \multirow{2}{*}{\multicolumn{3}{|c|}{$\begin{array}{c}\begin{array}{c}\text { Coal Consumption } \\
\text { Coefficients }\end{array} \\
\left(\mathrm{th}^{-1}\right) \\
\end{array}$}} & \multirow{2}{*}{\multicolumn{3}{|c|}{$\begin{array}{c}\text { No }{ }_{x} \text { Emission Coefficients } \\
\left(10 \mathrm{e}^{-7} \mathrm{th}^{-1}\right)\end{array}$}} & \multirow{2}{*}{\multicolumn{2}{|c|}{$\begin{array}{c}\begin{array}{c}\text { Lower and Upper } \\
\text { Limits }\end{array} \\
(\mathrm{MW})\end{array}$}} & \multirow{3}{*}{$\begin{array}{c}\begin{array}{c}\text { On-grid Power } \\
\text { Tariff }\end{array} \\
\text { (Cent/kWh) } \\
-\end{array}$} \\
\hline & & & & & & & & & \\
\hline & $a_{j}$ & $b_{j}$ & $c_{j}$ & $u_{j}$ & $v_{j}$ & $w_{j}$ & $\boldsymbol{P}_{\text {jmin }}$ & $\boldsymbol{P}_{\text {jmax }}$ & \\
\hline 1 & 0.000175 & 0.11 & 3 & 6.49 & 5.554 & 4.091 & 310 & 570 & 4.40 \\
\hline 2 & 0.00023 & 0.15 & 5 & 5.638 & 6.047 & 2.543 & 250 & 425 & 3.26 \\
\hline 3 & 0.000116 & 0.07 & 7 & 4.586 & 5.094 & 4.257 & 350 & 700 & 4.07 \\
\hline $4 a$ & -0.000039 & 0.29 & 5.3 & 3.718 & 3.905 & 5.859 & & & \\
\hline $4 b$ & a & $\mathrm{b}$ & 6.43 & 3.624 & -3.55 & 5.739 & 260 & 680 & 3.26 \\
\hline 5 & 0.00012 & 0.12 & 5 & 4.586 & 5.094 & 4.258 & 325 & 660 & 4.40 \\
\hline
\end{tabular}

The area has five coal-fired units. No. 4 is retrofitted to solar-assisted coal-fired units. The retrofitted system is fictitious based on the real parameters. The parameters of five units are shown in Table 1.

Table 1. Parameters for the case study.

Note: $\mathrm{a}=-(0.000005662+0.00000003497 \mathrm{DNI}), \mathrm{b}=0.2707-0.00004014 \mathrm{DNI}+0.00000003023 \mathrm{DNI}^{2}$, DNI is the Direct Normal Irradiance, $4 \mathrm{a}$ stands for the original unit, $4 \mathrm{~b}$ stands for the retrofitted unit.

On the basis of the parameters of No. 4 unit and collector and the values of DNI (direct normal insolation), the parameters of No. 4 unit are fitted to the function of load and DNI by using MATLAB. 
The results are presented in Table 1. The system of the retrofitted unit is the same as the solar-assisted coal-fired system in Figure 1. The parameters of No. 4 unit and collector are shown in Tables 2 and 3 , respectively.

Table 2. Parameters of No. 4 unit.

\begin{tabular}{ccccccc}
\hline Parameters & Units & \multicolumn{5}{c}{ Values } \\
\hline Load & $\%$ & 100 & 85 & 75 & 50 & 45 \\
Capacity & $\mathrm{MW}$ & 600.00 & 561.09 & 495.00 & 330.00 & 264.00 \\
Parameters of main steam & $\mathrm{Mpa} /{ }^{\circ} \mathrm{C}$ & $24.2 / 566$ & $24.2 / 566$ & $23.5 / 566$ & $15.9 / 566$ & $13.3 / 566$ \\
Reheat temperature & ${ }^{\circ} \mathrm{C}$ & 566 & 566 & 566 & 566 & 566 \\
Feedwater mass flowrate & $\mathrm{t} / \mathrm{h}$ & 1836.5 & 1552.2 & 1360.1 & 899.0 & 733.3 \\
Condenser pressure & $\mathrm{kpa}$ & 4.9 & 4.9 & 4.9 & 4.9 & 4.9 \\
Exhaust specific enthalpy & $\mathrm{kJ} / \mathrm{kg}$ & 2314.7 & 2347 & 2369.4 & 2440.1 & 2469.1 \\
Designed coal consumption rate & $\mathrm{g} / \mathrm{kWh}$ & 270.9 & 275.7 & 278.8 & 293.3 & 298.3 \\
\hline
\end{tabular}

Table 3. Parameters of collector.

\begin{tabular}{ccc}
\hline Parameters & Units & Values \\
\hline Width/Length & $\mathrm{m}$ & $5 / 47.1$ \\
The number of Loop & - & 70 \\
The number of SCA (solar collector assembly) in Loop & - & 8 \\
Collector array pitch & $\mathrm{m}$ & 15 \\
Collector area & $\mathrm{m}^{2}$ & 263,200 \\
The total area & $\mathrm{m}^{2}$ & $1,052,800$ \\
\hline
\end{tabular}

This study was based on the DNI value in Lhasa at a latitude of $29.60 \mathrm{~N}$, longitude of $91.10 \mathrm{E}$, and elevation of $3658 \mathrm{~m}$ in Tibet Province, one of the highest solar irradiation areas in China. In this paper, the values of DNI in June 25 are used to calculate the coal consumption of the units. The DNI values are shown in Figure 2.

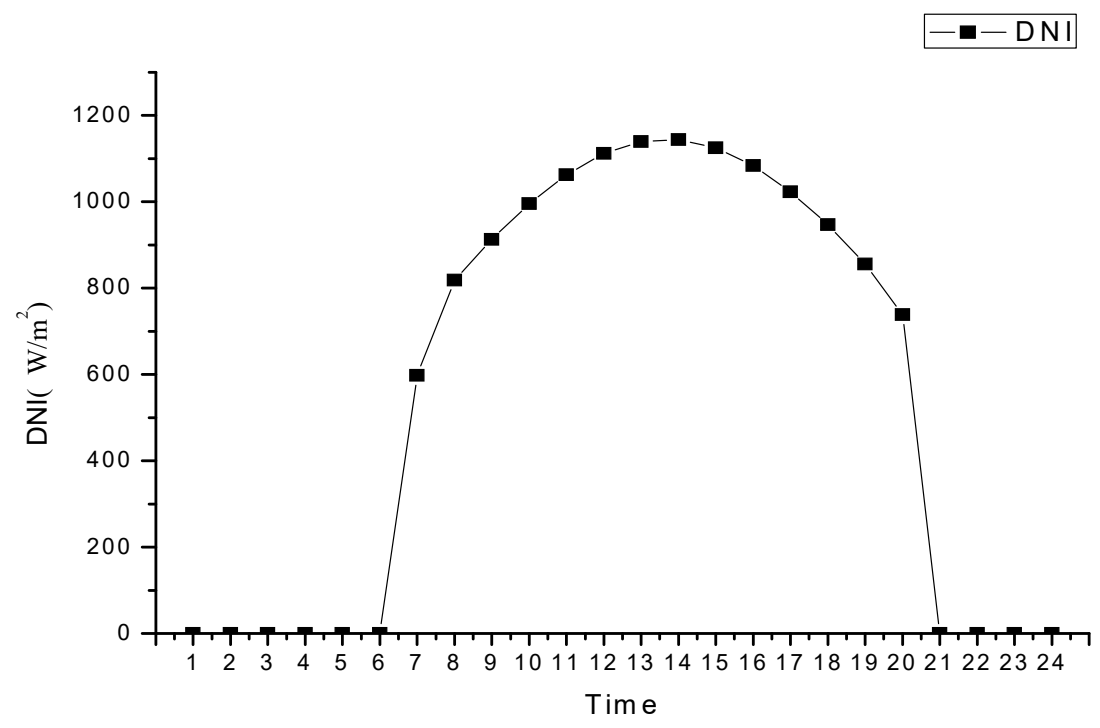

Figure 2. Values of DNI within $24 \mathrm{~h}$.

The power load demands in this area are shown in Figure 3; $w$ is chosen as $w=(1 / 3,1 / 3,1 / 3)$. To simplify the calculation, the loss of grid is ignored. 


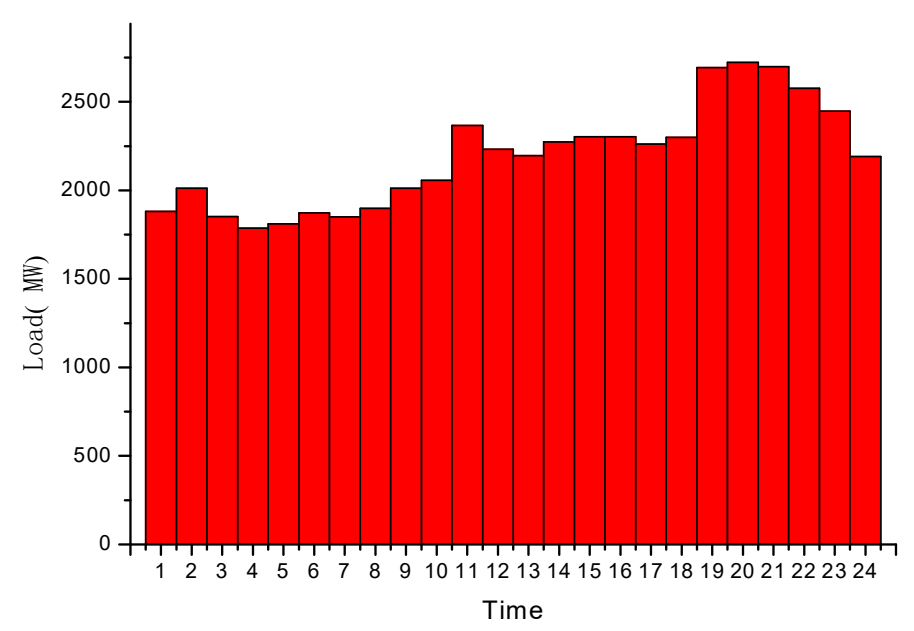

Figure 3. Power load demands within $24 \mathrm{~h}$.

\subsection{Results}

When the results of $\mathrm{w}=(1 / 3,1 / 3,1 / 3)$, the parameters of this No. 4 original unit (OU) and retrofitted unit (RU) are shown in Table 4 . More detailed values of each unit load allocation are shown in Table A1 in the Appendix A.

Table 4. Parameters of this No. 4 original unit (OU) and retrofitted unit (RU).

\begin{tabular}{cccc}
\hline \multirow{2}{*}{ No. 4 Unit } & Coal Consumption & $\mathbf{N O}_{\mathbf{x}}$ Emission & Power Costs \\
\cline { 2 - 4 } & $\mathbf{t d}^{\mathbf{- 1}}$ & $\mathbf{t d}^{\mathbf{- 1}}$ & $\mathbf{\$ d}^{\mathbf{- 1}}$ \\
\hline OU & $10,924.4$ & 11.33 & $2,023,434.1$ \\
RU & $10,699.9$ & 11.29 & $2,020,505.0$ \\
\hline
\end{tabular}

Table 4 shows that the coal consumption of units is reduced by approximately $2.05 \%$ from $10924.4 \mathrm{t}$ to $10699.9 \mathrm{t}$ per day. The $\mathrm{NO}_{\mathrm{x}}$ emission decreases by approximately $0.45 \%$ from $11.33 \mathrm{t}$ to $11.29 \mathrm{t}$ per day. The power costs are reduced by approximately $0.14 \%$ from $\$ 2,023,434.1$ to $\$ 2,020,505.0$ per day. Therefore, coal consumption has a greater degree of decline, while $\mathrm{NO}_{\mathrm{x}}$ emissions and power cost decline are not obvious. This result demonstrates that the development of solar-assisted coal-fired units can effectively deal with resource exhaustion, environmental pollution, and other issues from energy, environmental, and economic aspects.

The loads of the original and retrofitted units are shown in Figure 4.

Figure 4 shows that the loads of units changing with time are both consistent with the power demand in this region. In periods 1 to 6 , the loads of the original and retrofitted units are basically the same because the value of DNI is 0 in both original and retrofitted units. In periods 7 to 18 , the loads of the retrofitted unit are higher than those of the original unit. With the increase or decrease in DNI, the difference between the loads of two units also shows a corresponding change. In period 11, the difference between the loads of the two units decreases because the load of the retrofitted unit has reached the upper limit of the unit. In period 14, DNI reaches a maximum of $1143.96 \mathrm{MW} / \mathrm{m}^{2}$. The gap between two units also reaches a maximum of $40.64 \mathrm{MW}$. In periods 19 and 20, the loads of the original and retrofitted units have reached the upper limit of the unit. In periods 21 to 24 , DNI is 0 , and the loads of the original and retrofitted units are similar. 


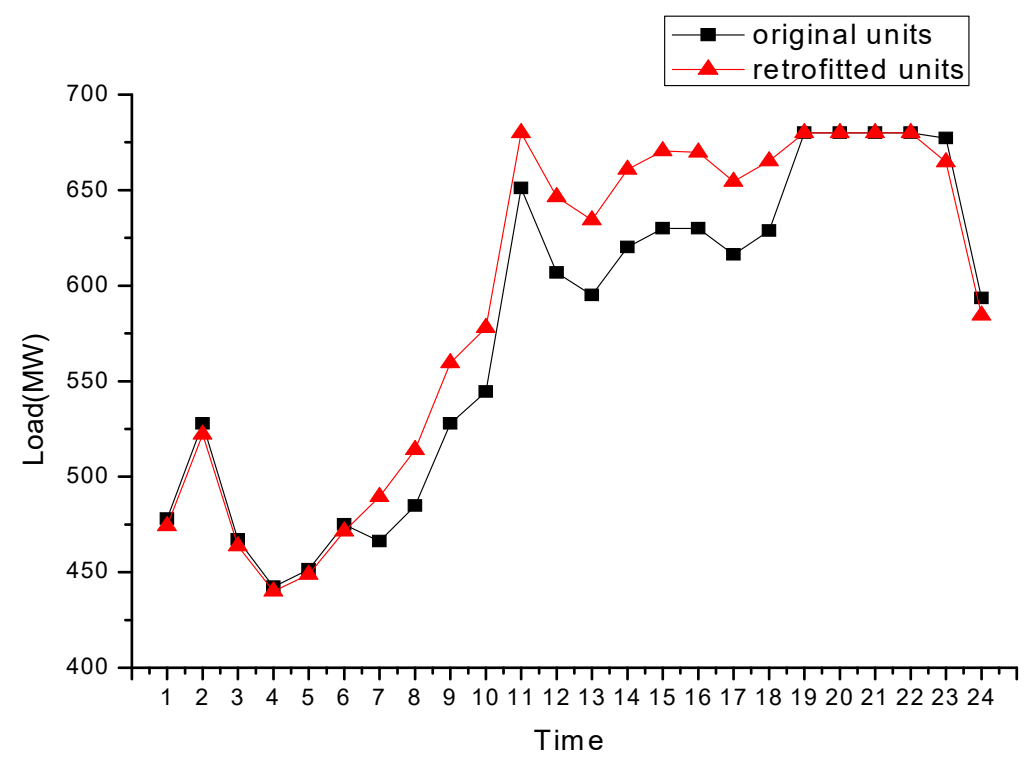

Figure 4. Load curves of No. 4 unit before and after reconstruction.

In periods 7 to 20 , the loads for the units changing between the original and retrofitted units is shown in Figure 5.

Figure 5 shows that the load of No. 4 unit is higher after the coal-fired unit is retrofitted into the solar-assisted coal-fired unit in the presence of solar radiation. Nevertheless, the loads are lower for the remaining units. Thus, under the multi-objective optimal condition, the advantages of the solar-assisted coal-fired unit are higher than those of the coal-fired unit. Therefore, the use of solar-assisted coal-fired power generation units should be prioritized when both coal-fired units and solar-assisted coal-fired units are present in a region.

For periods 7, 11, and 14, load ratios of five units are shown in Figure 6.

As shown in Figure 6, in periods 7, 11, and 14, the loads of No. 4 unit have increased by $1.27 \%$, $1.57 \%$, and $1.79 \%$, respectively. With increasing DNI values, the gap of loads between the coal-fired unit and solar-assisted coal-fired unit also increases.

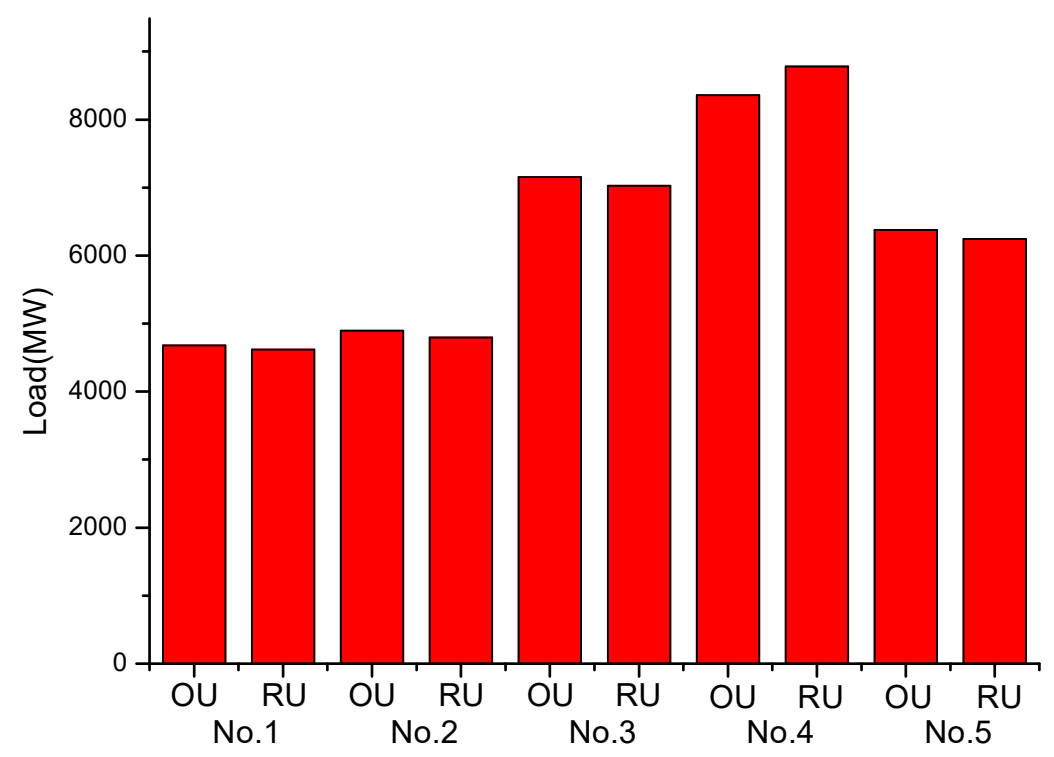

Figure 5. Load of units changing before and after reconstruction. 


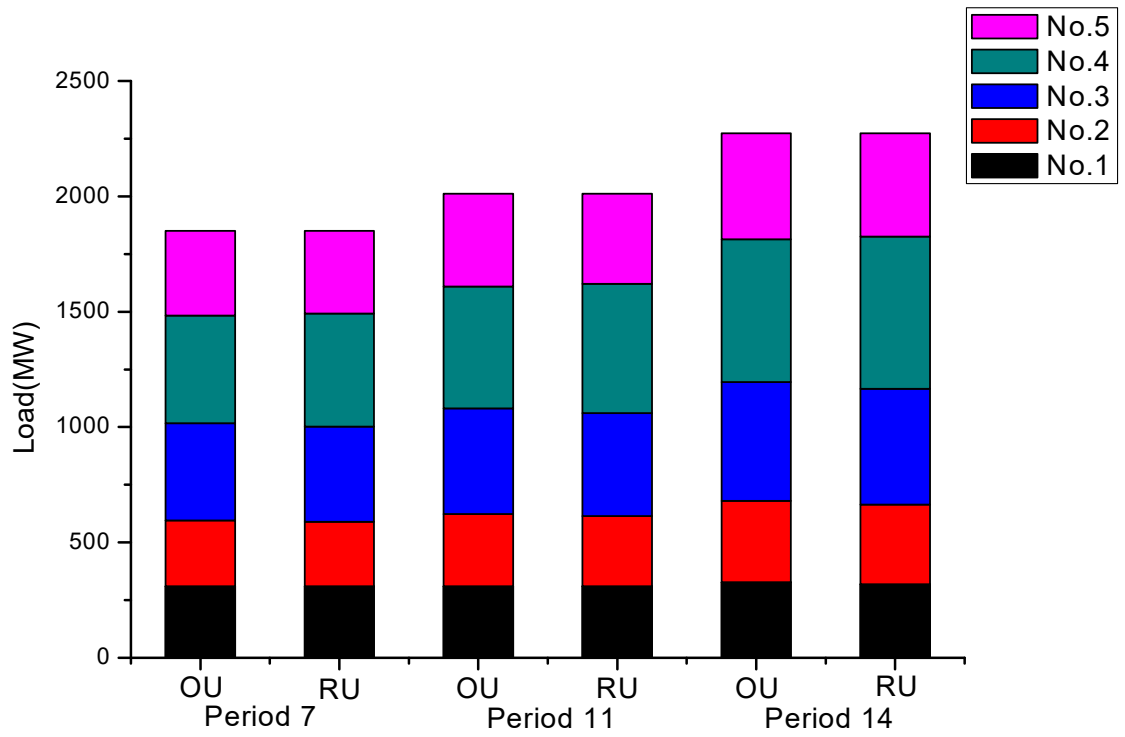

Figure 6. Load ratio of five units.

\section{Uncertainty Analysis}

Uncertainty analysis analyzes every factor that affects the project. Most of the basic data used in the evaluation process, such as investment, production, capital, revenue, and so on, are based on the calculation of forecasts and estimates, and it is assumed that these parameters remain unchanged in the calculation period. Decisions made on the basis of these conditions are called decisive decisions. However, due people's awareness of the limitations of predictions and the limited availability of information, these data and the actual situation may be different, thus leading to uncertainty. To reduce the risk of uncertainty and mistakes in the project, the impact of various uncertainties on the project must be analyzed. In the model building and solving process, some parameters are assumed. To match the model with the actual situation, the model requires uncertainty analysis.

\subsection{Effects of Weighted Coefficients}

The weighted coefficients are decided by the importance of different objectives. In this study, three weighted vectors are considered: $(1 / 3,1 / 3,1 / 3),(0.5,0.25,0.25)$, and $(0.8,0.1,0.1)$. The results are shown in Table 5.

Table 5. Effects of weighted vector on the results.

\begin{tabular}{ccccccc}
\hline \multirow{2}{*}{ Weighted Vector } & \multicolumn{2}{c}{ Coal Consumption } & \multicolumn{2}{c}{ NO $_{\mathbf{x}}$ Emission } & \multicolumn{2}{c}{ Power Costs } \\
\cline { 2 - 8 } & \multicolumn{2}{c}{$\mathbf{t d}^{-\mathbf{1}}$} & \multicolumn{2}{c}{$\mathbf{t d}^{\mathbf{- 1}}$} & \multicolumn{2}{c}{$\mathbf{S d}^{\mathbf{- 1}}$} \\
\cline { 2 - 8 } & $\mathbf{O U}$ & $\mathbf{R U}$ & $\mathbf{O U}$ & $\mathbf{R U}$ & $\mathbf{O U}$ & $\mathbf{R U}$ \\
\hline$(1 / 3,1 / 3,1 / 3)$ & $10,924.4$ & $10,699.9$ & 11.33 & 11.29 & $2,023,434.1$ & $2,020,505.0$ \\
$(0.5,0.25,0.25)$ & $10,824.4$ & $10,597.7$ & 11.42 & 11.38 & $2,033,382.7$ & $2,028,780.6$ \\
$(0.8,0.1,0.1)$ & $10,626.9$ & $10,433.4$ & 12.00 & 11.85 & $2,065,198.3$ & $2,051,382.3$ \\
\hline
\end{tabular}

As shown in Table 5, the coal consumption, $\mathrm{NO}_{\mathrm{x}}$ emissions, and power costs decline after the No. 4 unit is retrofitted under different weighted vectors. When the weighted vector transforms from $(1 / 3,1 / 3,1 / 3)$ to $(0.8,0.1,0.1)$, the coal consumption of the original unit declines by $2.72 \%$, and the $\mathrm{NO}_{\mathrm{x}}$ emissions and power costs increase by $5.91 \%$ and $2.06 \%$, respectively. The coal consumption of the retrofitted unit declines by $2.49 \%$, and the $\mathrm{NO}_{\mathrm{x}}$ emissions and power costs increase by $5.00 \%$ and $1.53 \%$, respectively. A comparison of the two data sets show that the change in the parameters of the retrofitted unit is less than that in the parameters of the original unit. This shows that small changes in the parameters of the solar-assisted coal-fired units are conducive to the operation stability of the unit. 
The impact of weighting coefficients for the optimal solution is shown in Figure 7.

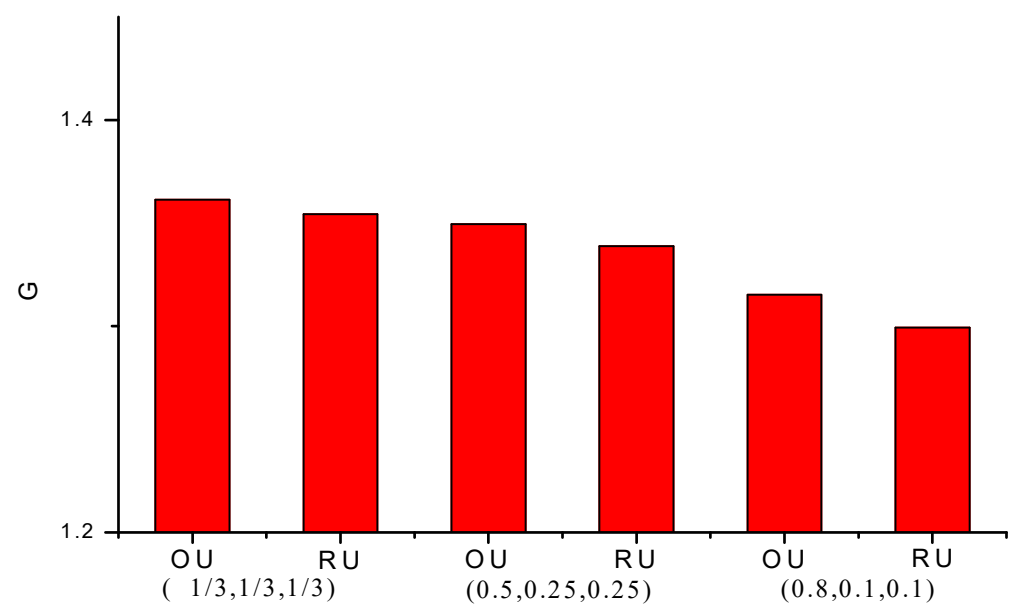

Figure 7. Impact of weighting coefficients for the optimal solution.

Figure 7 shows that the optimal solution of the solar-assisted coal-fired unit is less than that of the coal-fired unit with the same weighted vectors. The smaller the optimal solution, the better the performance of the unit. Thus, the performance of the solar-assisted coal-fired unit is better than that of the coal-fired unit. As the weight coefficients of coal consumption increase, the optimal solution decreases. This shows that among these three weighting coefficients, the weighting coefficients of coal consumption have the most important influence on the optimal solution.

\subsection{Effects of on-Grid Power Tariff}

In China, solar thermal power generation has not entered the commercial stage. The current on-grid power tariff of solar-assisted coal-fired units is not clearly defined. However, a large number of photovoltaic power generators have been put into use, so uncertainty analysis calculation refers to the PV (solar photovoltaic) on-grid power tariff. This paper selected 3.26, 6.52, 9.77, 13.03, and $16.29 \mathrm{cent} / \mathrm{kWh}$ as the on-grid power tariff for solar-assisted coal-fired units. The results are shown in Table 6.

Table 6. Effects of the on-grid power tariff on the results.

\begin{tabular}{cccc}
\hline On-grid Tariff & Coal Consumption & $\mathbf{N O}_{\mathbf{x}}$ Emission & Power Costs \\
\hline Cent/ $\mathbf{k W h}$ & $\mathbf{t d}^{\mathbf{- 1}}$ & $\mathbf{t d}^{\mathbf{- 1}}$ & $\mathbf{S d}^{\mathbf{- 1}}$ \\
\hline 3.26 & $10,699.9$ & 11.28 & $2,020,505.0$ \\
6.52 & $10,681.9$ & 11.39 & $2,416,605.0$ \\
9.77 & $10,677.2$ & 11.74 & $2,655,308.3$ \\
13.03 & $10,689.8$ & 12.07 & $2,825,889.1$ \\
16.29 & $10,699.5$ & 12.31 & $2,982,161.8$ \\
\hline
\end{tabular}

Table 6 shows a nonlinear relationship between coal consumption and on-grid tariff, but power purchase costs and $\mathrm{NO}_{\mathrm{x}}$ emissions increase with increasing tariff amount. When the tariff decreases from $16.29 \mathrm{cent} / \mathrm{kWh}$ to $3.26 \mathrm{cent} / \mathrm{kWh}, \mathrm{NO}_{\mathrm{x}}$ emissions drop by approximately $8.38 \%$ from $12.31 \mathrm{t}$ to $11.28 \mathrm{t}$ per day. In addition, the cost of purchasing electricity decreases by $32.25 \%$ from $\$ 2,982,161.8$ to $\$ 2,020,505.0$ per day.

The impact of the on-grid power tariff on the optimal solution is shown in Figure 8. 


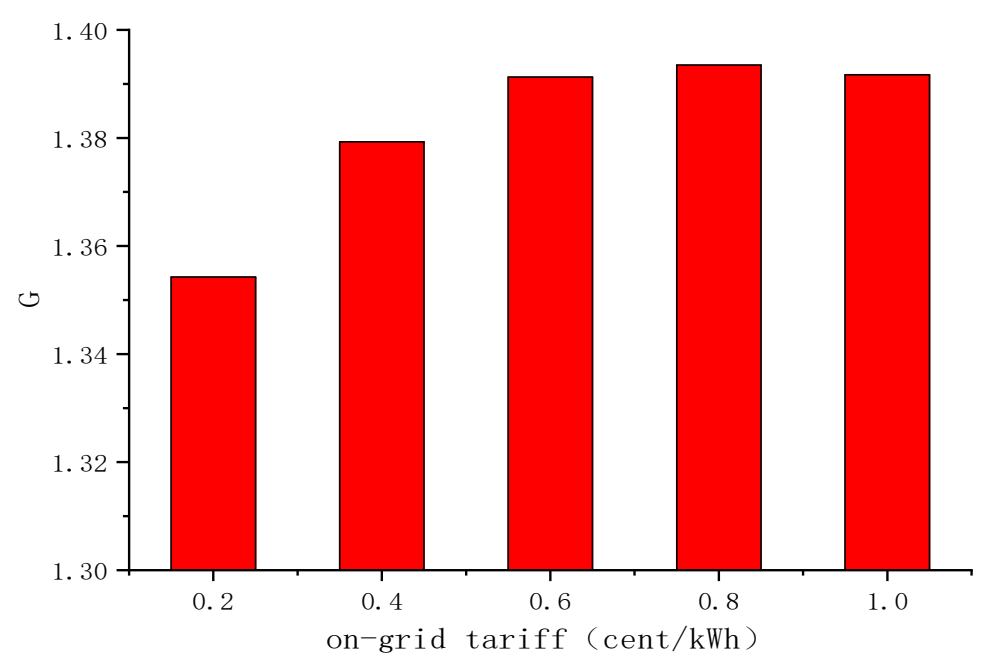

Figure 8. Impact of on-grid power tariff on the optimal solution.

As the tariff increases, the optimal solution also increases. The optimal solution finally stabilizes near 1.39. As the technology of the solar-assisted coal-fired units mature, their tariff gradually reduces. Therefore, the advantage of solar-assisted coal-fired units will become more apparent.

\section{Conclusions}

In this study, a coal-fired unit in a particular area is retrofitted to solar-assisted coal-fired units. The other remaining units are not changed. Under the given power demand, the multi-objective model considers coal consumption, $\mathrm{NO}_{\mathrm{x}}$ emissions, and power purchase cost. The singular weighted method combined with the MATLAB toolbox is used to find the optimal solution in the multi-objective function. Thus, the changes in each unit's load before and after the No. 4 unit is retrofitted are compared and analyzed under optimal solution conditions.

The original and retrofitted unit loads are compared over $24 \mathrm{~h}$. Results show that the loads of the solar-assisted coal-fired unit are higher than those of the coal-fired unit. With the increase in solar radiation, the gap between the loads of the two units also increases. The loads of five units before and after the No. 4 unit is retrofitted are compared under the solar radiation. The loads of the No. 4 unit increase, and the loads of the other units decrease.

In addition, uncertainty analysis in this section discusses the impact of weighting coefficients and on-grid power tariff changes on the results. With the increase in the weighted coefficient of coal consumption, the optimal solution decreases. Investigation of the on-grid power tariff shows that the optimal solution gradually declines as the tariff decreases.

Through this study, compared to coal-fired units, solar-assisted coal-fired units have an advantage in terms of energy saving and emission reduction. Therefore, the government should encourage and support the development of solar-assisted coal-fired units. The methods described in this paper may also be used to solve other problems. In real life, this method can be used to solve the load dispatch problem of this area according to the specific circumstances of units, DNI values, and power load. Then, recommendations on the regional distribution of load between units can be proposed.

Author Contributions: All of the authors have contributed to this research. The original ideas were provided by R.Z. and Y.H. The calculations and energy performance analysis were performed by L.F. and C.L. The revision of the draft was guided by R.Z. and Y.Y.

Funding: This research was funded by National Major Fundamental Research Program of China (No. 2015CB251505), China National Natural Science Foundation (No. 51776063), the Fundamental Research Funds for the Central Universities (2016YQ04), and China Scholarship Council.

Conflicts of Interest: The authors declare no conflict of interest. 


\section{Nomenclature}

$\begin{array}{llll}a_{j}, b_{j}, c_{j} & \text { coal consumption coefficients } & H & \text { symmetric matrix } \\ u_{j}, v_{j}, w_{j} & \text { pollutant emission coefficients } & A & \text { matrix for linear inequality constraints } \\ \rho_{j} & \text { power purchase costs } & B & \text { vector for linear inequality constraints } \\ P_{j} & \text { power output of the existing power } & A_{e q} & \text { matrix for linear equality constraints } \\ P_{D} & \text { generating units } & B_{e q} & \text { vector for linear equality constraints } \\ P_{L} & \text { electricity demand for the grid } & x_{m} & \text { vector of lower bounds } \\ P_{j \min } & \text { grid loss } & X_{m} & \text { vector of upper bounds } \\ P_{j \max } & \text { lower limit for units } & x_{0} & \text { initial point for x } \\ f & \text { upper limit for units } & \text { OU } & \text { original unit } \\ & \text { vector } & \text { RU } & \text { retrofitted unit }\end{array}$

\section{Appendix A Appendix}

Table A1. Each unit load allocation of No. 4 original unit (OU) and retrofitted unit (RU).

\begin{tabular}{ccccccccccc}
\hline Unit No. & \multicolumn{1}{c}{ P1(MW) } & \multicolumn{2}{c}{ P2(MW) } & \multicolumn{2}{c}{ P3(MW) } & \multicolumn{2}{c}{ P4(MW) } & \multicolumn{2}{c}{ P5(MW) } \\
\hline Time & OU & RU & OU & RU & OU & RU & OU & RU & OU & RU \\
\hline 1 & 310 & 310 & 291 & 292 & 429 & 430 & 478 & 474 & 373 & 375 \\
2 & 310 & 310 & 313 & 314 & 459 & 461 & 528 & 522 & 403 & 405 \\
3 & 310 & 310 & 286 & 287 & 422 & 423 & 467 & 464 & 367 & 368 \\
4 & 310 & 310 & 275 & 276 & 407 & 408 & 442 & 440 & 352 & 353 \\
5 & 310 & 310 & 279 & 280 & 413 & 414 & 451 & 449 & 358 & 359 \\
6 & 310 & 310 & 289 & 290 & 427 & 428 & 475 & 471 & 372 & 373 \\
7 & 310 & 310 & 286 & 279 & 422 & 413 & 466 & 490 & 366 & 358 \\
8 & 310 & 310 & 294 & 286 & 433 & 422 & 485 & 514 & 378 & 367 \\
9 & 310 & 310 & 313 & 304 & 459 & 447 & 528 & 559 & 403 & 392 \\
10 & 310 & 310 & 320 & 311 & 469 & 456 & 544 & 578 & 413 & 401 \\
11 & 340 & 334 & 366 & 360 & 532 & 524 & 651 & 680 & 476 & 468 \\
12 & 322 & 314 & 347 & 339 & 506 & 494 & 607 & 647 & 450 & 439 \\
13 & 317 & 310 & 342 & 333 & 499 & 487 & 595 & 634 & 443 & 431 \\
14 & 327 & 319 & 353 & 344 & 514 & 502 & 620 & 661 & 458 & 446 \\
15 & 332 & 323 & 357 & 349 & 520 & 508 & 630 & 671 & 464 & 452 \\
16 & 332 & 324 & 357 & 349 & 520 & 508 & 630 & 670 & 464 & 453 \\
17 & 326 & 318 & 351 & 343 & 512 & 500 & 616 & 654 & 456 & 445 \\
18 & 331 & 324 & 357 & 349 & 519 & 508 & 629 & 665 & 463 & 453 \\
19 & 402 & 402 & 425 & 425 & 621 & 621 & 680 & 680 & 565 & 565 \\
20 & 410 & 410 & 425 & 425 & 632 & 632 & 680 & 680 & 576 & 576 \\
21 & 404 & 404 & 425 & 425 & 624 & 623 & 680 & 680 & 567 & 567 \\
22 & 377 & 377 & 405 & 405 & 585 & 585 & 680 & 680 & 529 & 529 \\
23 & 351 & 354 & 378 & 381 & 548 & 552 & 677 & 665 & 492 & 496 \\
24 & 316 & 318 & 341 & 343 & 498 & 500 & 593 & 584 & 442 & 445 \\
\hline & & & & & & & & & &
\end{tabular}

\section{References}

1. Yongping, Y.; Rongrong, Z.; Liqiang, D.; Masek, O.; Oakey, J. Study on multi-objective optimization of load dispatch including renewable energy and CCS technologies. Int. J. Energy Res. 2010, 34, 702-715. [CrossRef]

2. Bakos, G.C.; Tsechelidou, C. Solar aided power generation of a $300 \mathrm{MW}$ lignite fired power plant combined with line-focus parabolic trough collectors field. Renew. Energy 2013, 60, 540-547. [CrossRef]

3. China Electric Council. 2018. Available online: http://www.cec.org.cn/d/file/guihuayutongji/tongjxinxi/ niandushuju/2019-01-22/4fedb4c956f6059c5998913b10a6233a.pdf (accessed on 16 February 2019).

4. Ruilin, W.; Jie, S.; Hui, H.; Hongguang, J. Comprehensive evaluation for different models of Solar-aided coal-fired power generation system under common framework regarding both Coal-savability and efficiency-promotability. Energy 2018, 143, 151-167.

5. Desai, N.B.; Kedare, S.B.; Bandyopadhyay, S. Optimization of design radiation for concentrating solar thermal power plants without storage. Sol. Energy 2014, 107, 98-112. [CrossRef] 
6. Raul, A.; Jain, M.; Gaikwad, S.; Saha, K. Modelling and experimental study of latent heat thermal energy storage with encapsulated PCMs for solar thermal applications. Appl. Therm. Eng. 2018, 143, 415-428. [CrossRef]

7. Lakhani, S.; Raul, A.; Saha, S. Dynamic modelling of ORC-based solar thermal power plant integrated with multitube shell and tube latent heat thermal storage system. Appl. Therm. Eng. 2017, 123, 458-470. [CrossRef]

8. Corgnale, C.; Hardy, B.; Motyka, T.; Zidan, R.; Teprovich, J.; Peters, B. Screening analysis of metal hydride based thermal energy storage systems for concentrating solar power plants. Renew. Sustain. Energy Rev. 2014, 38, 821-833. [CrossRef]

9. Yogev, R.; Kribus, A. Operation strategies and performance of solar thermal power plants operating from PCM storage. Sol. Energy 2013, 95, 170-180. [CrossRef]

10. Ehrhart, B.; Gill, D. Evaluation of Annual Efficiencies of High Temperature Central Receiver Concentrated Solar Power Plants with Thermal Energy Storage. Energy Procedia 2014, 49, 752-761. [CrossRef]

11. Oró, E.; Gil, A.; de Gracia, A.; Boer, D.; Cabeza, L.F. Comparative life cycle assessment of thermal energy storage systems for solar power plants. Renew. Energy 2012, 44, 166-173. [CrossRef]

12. Hu, E.; Yang, Y.; Nishimura, A.; Yilmaz, F.; Kouzani, A. Solar thermal aided power generation. Appl. Energy 2010, 87, 2881-2885. [CrossRef]

13. Yang, Y.; Yan, Q.; Zhai, R.; Kouzani, A.; Hu, E. An efficient way to use medium-or-low temperature solar heat for power generation-integration into conventional power plant. Appl. Therm. Eng. 2011, 31, 157-162. [CrossRef]

14. Hong, H.; Peng, S.; Zhao, Y.; Liu, Q.; Jin, H. A Typical Solar-coal Hybrid Power Plant in China. Energy Procedia 2014, 49, 1777-1783. [CrossRef]

15. Bhattacharjee, K.; Bhattacharya, A.; Halder nee Dey, S. Solution of Economic Emission Load Dispatch problems of power systems by Real Coded Chemical Reaction algorithm. Int. J. Electr. Power Energy Syst. 2014, 59, 176-187. [CrossRef]

16. Jeddi, B.; Vahidinasab, V. A modified harmony search method for environmental/economic load dispatch of real-world power systems. Energy Convers. Manag. 2014, 78, 661-675. [CrossRef]

17. Leena, D.; Krishna, T.C.; Mohan, L.K. Dynamic Economic Load Dispatch using Levenberg Marquardt Algorithm. Energy Procedia 2018, 144, 95-103.

18. Coelho, L.D.S.; Lee, C.S. Solving economic load dispatch problems in power systems using chaotic and Gaussian particle swarm optimization approaches. Int. J. Electr. Power Energy Syst. 2008, 30, $297-307$. [CrossRef]

19. Li, M.S.; Wu, Q.H.; Ji, T.Y.; Rao, H. Stochastic multi-objective optimization for economic-emission dispatch with uncertain wind power and distributed loads. Electr. Power Syst. Res. 2014, 116, 367-373. [CrossRef]

20. Mondal, S.; Bhattacharya, A. Multi-objective economic emission load dispatch solution using gravitational search algorithm and considering wind power penetration. Int. J. Electr. Power Energy Syst. 2013, 44, 282-292. [CrossRef]

21. Aghaei, J.; Niknam, T.; Azizipanah-Abarghooee, R.; Arroyo, J.M. Scenario-based dynamic economic emission dispatch considering load and wind power uncertainties. Int. J. Electr. Power Energy Syst. 2013, 47, 351-367. [CrossRef]

22. Modarresi, M.S.; Xie, L.; Campi, M.G.; Simone, C.; Algo, T.; Anupam, K. PR Scenario-based Economic Dispatch with Tunable Risk Levels in High-renewable Power Systems. IEEE Trans. Power Syst. $2018,1$. [CrossRef]

23. Zhu, Y.; Wang, J.; Qu, B. Multi-objective economic emission dispatch considering wind power using evolutionary algorithm based on decomposition. Int. J. Electr. Power Energy Syst. 2014, 63, 434-445. [CrossRef]

24. Rizk-Allah, R.M.; El-Sehiemy, R.A.; Wang, G.G. A novel parallel hurricane optimization algorithm for secure emission/economic load dispatch solution. Appl. Soft Comput. 2018, 63, 206-222. [CrossRef]

25. Roy, S. The maximum likelihood optima for an economic load dispatch in presence of demand and generation variability. Energy 2018, 147, 915-923. [CrossRef]

26. Modarresi, M.S.; Xie, L. An operating reserve risk map for quantifiable reliability performances in renewable power systems. In Proceedings of the 2014 IEEE PES General Meeting | Conference \& Exposition, National Harbor, MD, USA, 27-31 July 2014. 
27. Li, J.F.; Zhang, B.H.; Liu, Y.F.; Wang, K.; Wu, X.S. Spatial evolution character of multi-objective evolutionary algorithm based on self-organized criticality theory. Phys. A Stat. Mech. Its Appl. 2012, 391, 5490-5499. [CrossRef]

28. Lu, Y.; Zhou, J.; Qin, H.; Wang, Y.; Zhang, Y. Environmental/economic dispatch problem of power system by using an enhanced multi-objective differential evolution algorithm. Energy Convers. Manag. 2011, 52, 1175-1183. [CrossRef]

29. Wu, L.H.; Wang, Y.N.; Yuan, X.F.; Zhou, S.W. Environmental/economic power dispatch problem using multi-objective differential evolution algorithm. Electr. Power Syst. Res. 2010, 80, 1171-1181. [CrossRef]

30. Siddiqi, U.F.; Shiraishi, Y.; Dahb, M.; Sait, S.M. A memory efficient stochastic evolution based algorithm for the multi-objective shortest path problem. Appl. Soft Comput. 2014, 14, 653-662. [CrossRef]

31. Peng, C.; Sun, H.; Guo, J. Multi-objective optimal PMU placement using a non-dominated sorting differential evolution algorithm. Int. J. Electr. Power Energy Syst. 2010, 32, 886-892. [CrossRef]

32. Ghasemi, A. A fuzzified multi objective interactive honey bee mating optimization for environmental/economic power dispatch with valve point effect. Int. J. Electr. Power Energy Syst. 2013, 49, 308-321. [CrossRef]

33. El-sobky, B.; Abo-elnaga, Y. Multi-objective economic emission load dispatch problem with trust-region strategy. Electr. Power Syst. Res. 2014, 108, 254-259. [CrossRef]

34. Hunt, B.R.; Lipsman, R.L.; Rosenberg, J.M.; Coombes, K.R.; Osborn, J.E.; Stuck, G.J. A Guide to MATLAB: For Beginners and Experienced Users; Cambridge University Press: Cambridge, UK, 2006.

(C) 2019 by the authors. Licensee MDPI, Basel, Switzerland. This article is an open access article distributed under the terms and conditions of the Creative Commons Attribution (CC BY) license (http://creativecommons.org/licenses/by/4.0/). 